\title{
Su bazlı boya atık suyu arıtımında bir adım ileri gelişmiş deneysel pH kontrol uygulaması
}

Şule Camcioğlu*, Baran Özyurt, Zehra Zeybek, Hale Hapoğlu

Ankara Üniversitesi, Mühendislik Fakültesi, Kimya Mühendisliği Bölümü, Dögol Caddesi, Tandoğan, 06100, Ankara, Türkiye

Ö N E Ç I K A N L A R

- Su bazlı boya atık suyu arıtımında $\mathrm{pH}$ kontrol

- Uygun kontrol edici tasarımı

- Deneysel pH kontrol uygulamasının arıtım verimine etkisi

Makale Bilgileri

Geliş: 14.08.2015

Kabul: 21.09.2015

DOI:

10.17341/gummfd.52934

Anahtar Kelimeler:

Su bazlı boya atık suyu,

koagülasyon,

bir adım ileri kontrol

\section{ÖZET}

Sanayi faaliyetlerinden kaynaklanan atık suların ve onların içerdikleri maddelerin doğrudan yeryüzü sularına, yeraltı sularına ve toprağa atılması sonucu oluşan kirliliğin önlenebilmesi açısından uygun alıcı ortamlara arıtılarak deşarj edilmesi gerekir. Yapılan çalışmada koagülasyon-flokülasyon yöntemi ile su bazlı boya atık suyunun arıtımı gerçekleştirilmiştir. En uygun koagülant ve ortam pH'ının belirlenmesi amaciyla $0,17,0,34,0,51,0,85,1,19 \mathrm{~g} / \mathrm{L}$ derişimlerinde $\mathrm{MgCl}_{2}, \mathrm{FeCl}_{3}$ ve $\mathrm{Al}_{2}\left(\mathrm{SO}_{4}\right)_{3}$ çöktürücüleri ile $\mathrm{pH} 7$, $8,9,10,11,12$ değerlerinde kesikli deneyler gerçekleştirilmiştir. En uygun çöktürme koşulları $25^{\circ} \mathrm{C}$ sıcaklık, pH 8, 0,68 g/L Al $\left(\mathrm{SO}_{4}\right)_{3}$ koagülant derişimi olarak belirlenmiş ve absorbans, bulanıklık ve kimyasal oksijen ihtiyacı (KOİ) giderimleri sırasıyla \%93,55, \%79,38, \%22,30 olarak elde edilmiştir. Su bazlı boya atık suyunun pH'ını koagülasyon prosesi boyunca istenen set noktasında sabit tutmak amaciyla bir adım ileri kontrol algoritması kullanılmıştır. pH'ın proses süresince 8 değerinde kontrol edilmesinin, kontrol edilmediği duruma göre absorbans, bulanıklık ve KOİ giderim verimlerini sırasıyla \%3,36, \% $14,11, \% 54,08$ oranında arttırdığı gözlemlenmiştir.

\section{Experimental application of one step ahead advanced $\mathrm{pH}$ control to water-based paint wastewater treatment}

\author{
H I G H L I G H T S
}

- $\mathrm{pH}$ control of water-based paint wastewater treatment

- Controller design

- Effect of experimental pH control on treatment efficiency

Article Info

Received: 14.08 .2015

Accepted: 21.09.2015

DOI

10.17341/gummfd.52934

Keywords:

Water-based paint

wastewater,

coagulation,

one step ahead control

\section{ABSTRACT}

Wastewaters and their ingredients which are formed by industrial activities must be treated before discharge into suitable receivers in order to prevent the pollution of surfacewater, groundwater and soilground. In the present work, water-based paint wastewater treatment is performed using chemical coagulation and flocculation methods. Batch experiments were performed for determination of optimum coagulant and $\mathrm{pH}$ conditions using $\mathrm{MgCl}_{2}, \mathrm{FeCl}_{3}$ ve $\mathrm{Al}_{2}\left(\mathrm{SO}_{4}\right)_{3}$ as coagulants at $0.17,0.34,0.51,0.85,1.19$ $\mathrm{g} / \mathrm{L}$ concentrations and at $7,8,9,10,11,12 \mathrm{pH}$ conditions. At $25^{\circ} \mathrm{C}, \mathrm{pH} 8$ and $0.68 \mathrm{~g} / \mathrm{L} \mathrm{Al}_{2}\left(\mathrm{SO}_{4}\right)_{3}$ coagulant concentration conditions absorbance, turbidity and chemical oxygen demand (COD) removal efficiencies are obtained as $93.55 \%, 79.38 \%$ and $22.30 \%$ respectively. One step ahead control algorithm is applied to the keep the $\mathrm{pH}$ constant at a desired value. It is observed that, control of $\mathrm{pH}$ at 8 during process was increased absorbance, turbidity and COD removal efficiencies by $3.36 \%, 14.11 \%, 54.08 \%$ respectively as compared with the uncontrolled case.

\section{GİRIŞ (INTRODUCTION)}

Boya üretiminde atık su temel olarak çeşitli organik ve inorganik bileşenlerin birbirleriyle temas ettiği karıştırıcıların, reaktörlerin, paketleme makinalarının ve zeminlerin temizlenme işlemleri sırasında meydana gelmektedir [1, 2]. Fiziksel, kimyasal ve biyolojik olaylar kirleticilerin kıyısal su alanlarındaki dağılımını etkilemektedir [3]. Zehirli yapısı ve bileşenlerinin kararlılığı nedeniyle alıcı ortamlara deşarj edilmesi tehdit oluşturan atık suların önce kirlilik yükünü azaltmak ve askıda katıları, metal iyonlarını ve mikroorganizmaları uzaklaştırmak için etkili ve ekonomik bir arıtım yapılması gerekmektedir [4, 5]. Su bazlı boya endüstrisi atık sularının arıtımında

\footnotetext{
*Sorumlu Yazar/Corresponding author: camcioglu@eng.ankara.edu.tr / Tel: 03122033465
} 
mikrofiltrasyon, adsorpsiyon, biyolojik aritım, Fenton, elektrooksidasyon, elektrokoagülasyon, membran ve koagülasyon-flokülasyon gibi çeşitli yöntemler kullanılmaktadır [2, 5-12]. Bu yöntemlerden koagülasyonflokülasyon atık su arıtımında yüksek giderim verimleri elde edilmesi bakımından dikkat çekmektedir. Söz konusu yöntemde, organik maddelerle birlikte askıda katıların giderimi sağlanırken atık sudan boyar maddelerin uzaklaştırılmasıyla da renk giderimi gerçekleştirilmektedir [11]. Tüm gerçek dinamik sistemlerde istenmeyen sıcaklık, basınç, pH değişimleri gibi çeşitli çevresel faktörlerden kaynaklanan belirsizlikler kaçınılmazdır [13]. Yapılan çalışmalarda kullanılan koagülantların asidik özelliğinden dolayı koagülasyon prosesi süresince $\mathrm{pH}$ düşüşü gözlenmiştir. Kolloidal parçacıkların kararlılıkları pH'taki düşüşten etkilenmiş ve bu parçacıklar düşük pH'ta çökme eğiliminde olmadıklarından dolayı istenen seviyede absorbans giderimi sağlanamamıştır. $\mathrm{Bu}$ nedenle kirlilik giderimi için koagülasyon prosesi boyunca $\mathrm{pH}^{\prime} 1$ istenen değerde tutmak amaciyla bir adım ileri kontrol algoritmasının uygulanması gerekli görülmüştür.

\section{KOAGÜLASYON-FLOKÜLASYON (COAGULATION-FLOCCULATION)}

Sulara kimyasal maddeler ekleyerek çökelme özellikleri çok iyi olmayan askıda katı madde veya kolloidlerin daha iyi çökebilen parçacıklar haline çevrilmesi yöntemi olan koagülasyon-flokülasyon evsel ve endüstriyel atık suların arıtılmasında kullanılan bir yöntemdir. Koagülant olarak siklıkla $\mathrm{Al}\left(\mathrm{SO}_{4}\right)_{3}, \mathrm{FeCl}_{3}, \mathrm{Fe}_{2}\left(\mathrm{SO}_{4}\right)_{3}, \mathrm{FeSO}_{4}$ ve $\mathrm{Ca}(\mathrm{OH})_{2}$ kullanılmaktadır [14]. Alüminyum ve demir tuzları sulardan kolloidal parçacıkların ve çözünmüş organik maddelerin gideriminde oldukça etkilidirler. Etki şekilleri genel olarak iki farklı mekanizma aracılığıyla açıklanmaktadır: negatif yüklü kolloidlerin yüklerinin katyonik hidroliz ürünleri tarafından nörtlenmesi ve safsızlıkların amorf hidroksit çökeleğinde birleşmesi. Bu mekanizmaların önemi $\mathrm{pH}$ ve koagülant miktarı gibi faktörlere bağlı olmaktadır. Çöken metal hidroksitlerinin yüzey yük karakteristikleri koagülasyonda büyük öneme sahiptir ve oksitlerle minerallere benzer şekilde görünür yüzey yükünün sıfır olduğu bir izoelektrik nokta göstermektedirler. İzoelektrik noktanın altındaki $\mathrm{pH}$ değerlerinde çökelti pozitif yüklü iken yüksek $\mathrm{pH}$ değerlerinde negatif yüklüdür. $\mathrm{pH}$ ile birlikte değişen yükler çöktürme prosesini önemli ölçüde etkilemektedir. Alüminyum için nötr pH'ta başlangıçta oluşturulan kolloidal çökelti pozitif yüklü ve dolayısıyla kolloidal olarak kararlıdır. pH, izoelektrik noktaya doğru arttırıldığında kararlılık azalmakta, parçacıklar büyük ve çökebilir floklar halinde topaklaşmaktadır [15]. Yapılan çalışmada koagülant olarak kullanılan $\mathrm{Al}_{2}\left(\mathrm{SO}_{4}\right)_{3}$ 'ün çöktürücü etkisi incelenecek olursa $\mathrm{Al}_{2}\left(\mathrm{SO}_{4}\right)_{3}$ suda bulunan doğal alkalinite ile reaksiyona girerek hidroliz olmakta ve Reaksiyon (R1)'de görüldüğü gibi $\mathrm{Al}(\mathrm{OH})_{3}$ oluşturmaktadır.

$\mathrm{Al}_{2}\left(\mathrm{SO}_{4}\right)_{3}+3 \mathrm{Ca}\left(\mathrm{HCO}_{3}\right)_{2} \rightarrow 2 \mathrm{Al}(\mathrm{OH})_{3}+3 \mathrm{CaSO}_{4}+6 \mathrm{CO}_{2}$
Oluşan $\mathrm{Al}(\mathrm{OH})_{3}$ jel görünümünde olup askıdaki katı taneciklerin adsorpsiyonu ile büyümektedir. Büyüme sonucunda tanecikler, ağırlıkları artacağından, hızla dibe çökerken üst kısımda arıtılmış atık su kalacaktır [16].

\section{BİR ADIM İLERİ KONTROL (ONE STEP AHEAD CONTROL)}

Gerçek proseslerde bir adım ileri kontrol uygulaması sınırlı olmakla birlikte literatürde yer alan çalışmalarda dolgulu damıtma kolonunda metanol-su karışımının üst ürün sıcaklığının, polistiren polimerizasyon reaktörünün sicaklığının, biyoreaktörde çoğalma ortamı sicaklığının, çözünmüş oksijen derişiminin ve glikoz derişiminin kontrolü gerçekleştirilmiştir [17-21]. Bir adım ileri kontrol stratejisi minimum olmayan faz sistemlerinin ve zaman gecikmeli sistemlerin kontrolü ile ilgilenmektedir. $\mathrm{Bu}$ tekniğin maliyet fonksiyonu Eşitlik (1) ile ifade edilmektedir.

$$
J(u, t)=\Xi\left\{(y(t+k)-r(t+k))^{2}+\lambda u(t)^{2}\right\}
$$

Gerçek sistemin kutup ve sıfırlarından birisi birim çemberin dışında ise sistem kararsızdır ve minimum olmayan faz özelliği gösterir. Bu tip kontrol edici tasarımı sistemi içten kararlı hale getirebilmekle birlikte, kararlılık seçilen $\lambda$ değerlerine bağlıdır. Bir adım ileri kontrol algoritmasının iyi bir set noktası takip karakteristiği vardır ve minimum olmayan faz sistemlerini kontrol etme yeteneğine sahiptir $[19,20]$. Ancak Eşitlik (1)'in kullanımıyla sıfırdan farklı set noktası varlığında sıfır yatışkın hale ulaşılamadığından modifiye edilmesi gerekmiş ve Eşitlik (2) elde edilmiştir.

$$
J(u, t)=\Xi\left\{(y(t+k)-r(t+k))^{2}+\lambda(\Delta u(t))^{2}\right\}
$$

$\mathrm{Bu}$ maliyet fonksiyonunu kullanan bir adım ileri kontrol tekniği, istenen amaca oldukça yakın kalmak için minimum bir çıktı değişimini sürdürürken, $\lambda$ 'yı mümkün olduğunca küçük alarak kapalı hat kararlılığını korumaya dayanır. Bu maliyet fonksiyonu genel olarak Eşitlik (3) ile ifade edilebilir.

$$
J(u, t)=\Xi\left\{\phi^{2}(t+k)\right\}
$$

Bir adım ileri kontrol yaklaşımı Eşitlik (3) ile genel olarak ifade edilen maliyet fonksiyonunu minimize etmek üzere Eşitlik (4) ile verilen bir $\phi(\mathrm{t}+\mathrm{k})$ sistem yalancı çıktısını kullanır.

$\phi(t+k)=P y(t+k)+Q u(t)-R r(t)$

Burada k zaman gecikimi, $\mathrm{r}(\mathrm{t})$ set noktası, $\mathrm{P}, \mathrm{Q}$ ve $\mathrm{R}$ geri kaydırma işlecinde $\left(\mathrm{z}^{-1}\right)$ iletim fonksiyonlarıdır. Yalancı çıtı $\phi(t+k)^{\prime}$ 'y elde etmek üzere $y(t+k)$ ile ifade edilen sistem çıktısının tanımlanması gerekmektedir. Kontrol edicilerin tasarımları sistem modeli doğru olarak elde 
edilmemişse zorlaşmaktadır [22]. Bu da doğrusal bir girdiçıktı modeli olarak tanımlanan sistem modelinin Eşitlik (5)'te verildiği gibi doğru bir şekilde oluşturulmasını gerektirir.

$$
\begin{aligned}
& y(t)+a_{1} y(t-1)+\ldots+a_{n_{a}} y\left(t-n_{a}\right)= \\
& b_{0} u(t-k)+b_{1} u(t-k-1)+\ldots+b_{n_{b}} u\left(t-k-n_{b}\right)
\end{aligned}
$$

Bu model kesikli transfer fonksiyonu olarak Eşitlik (6)'daki gibi ifade edilebilir.

$$
y(t)=\frac{B}{A} u(t-k)
$$

Burada B ve A polinomları, sirasiyla sistemin kutupları ve sıfırlarıdır. Eşitlik (6) ile verilen sistem modelinde sistem çıktısı $y(t)$ yük etkisi içermemektedir. Ancak prosesin kontrol edilen değişkeni üzerinde etkili olan rastgele yükler de sistem modelinde yer almalıdır. Buna göre rastgele yük ifadesini de içeren CARMA sistem modeli Eşitlik (7) ile ifade edilmiştir.

$$
y(t)=\frac{B}{A} u(t-k)+\frac{C}{A} e(t)
$$

Yalancı-çıktı ifadesinde (Eşitlik (4)), $y(t+k)$ sistem çıktısı yerine Eşitlik (7)'den değeri yazılırsa yalancı-çıktı ifadesi Eşitlik (8)'de görülen şekli alır.

$$
\phi(t+k)=P\left[\frac{B}{A} u(t)+\frac{C}{A} e(t+k)\right]+Q u(t)-R r(t)
$$

Eşitlik (8) düzenlenerek Eşitlik (9) elde edilir. Buna göre minimize edilecek maliyet fonksiyonu yalancı çıtının değişimi olacaktır (Eşitlik (3)).

$$
\phi(t+k)=\frac{P B+Q A}{A} u(t)+\frac{P C}{A} e(t+k)-R r(t)
$$

Bir adım ileri kontrol algoritması sistemi parçalara ayırmaktadır. Bunun için öncelikle hata terimi geçmişteki, şimdiki ve gelecekteki verileri içerecek şekilde parçalara ayrılarak Eşitlik (10)'daki gibi düzenlenir.

$$
\frac{P C}{A} e(t+k)=E e(t+k)+z^{-k} \frac{G}{A} e(t+k)
$$

Eşitlik (10)'un her iki tarafı A polinomu ile çarpılır ve düzenlenerek Eșitlik (11) elde edilir.

$$
P C=A E+z^{-k} G
$$

Polinomlar Eşitlik (12-17) ile ifade edilmektedir [19].

$$
A=1+a_{1} z^{-1}+\ldots+a_{n_{a}} z^{-n_{a}}
$$

$$
\begin{aligned}
& B=b_{0}+b_{1} z^{-1}+\ldots+b_{n_{b}} z^{-n_{b}} \\
& C=1+c_{1} z^{-1}+\ldots+c_{n_{c}} z^{-n_{c}} \\
& E=1+e_{1} z^{-1}+\ldots+e_{k-1} z^{-(k-1)} \\
& F=f_{0}+f_{1} z^{-1}+\ldots+f_{n_{f}} z^{-n_{f}} \\
& G=g_{0}+g_{1} z^{-1}+\ldots+g_{n_{g}} z^{-n_{g}}
\end{aligned}
$$

Eşitlik (11)'de yer alan AE ifadesinin, ofseti de içeren geliştirilmiş CARMA modelinden elde edilen değeri Eşitlik (18)'de verilmiştir.

$A y(t+k)=B u(t)+C e(t+k)+d$

Eşitlik (18)'in her iki tarafi E polinomu ile çarpılır ve Eşitlik (11)'de yerine yazılarak Eşitlik (19) oluşturulur.

$P C y(t+k)=B E u(t)+C E e(t+k)+E d+G y(t)$

Eşitlik (19)'un her iki tarafı C ile bölünerek Eşitlik (20) oluşturulur.

$P y(t+k)=\frac{B E}{C} u(t)+E e(t+k)+\frac{E d}{C}+\frac{G}{C} y(t)$

Eşitlik (20), sistem yalancı çıktısı ifadesinde (Eşitlik (4)) yerine yazılır ve düzenlenirse Eşitlik (21) elde edilir.

$\phi(t+k)=\frac{1}{C}[(B E+Q C) u(t)+G y(t)-C R r(t)+E d]+E e(t+k)$

$\phi(t+k)$ ifadesi iki bağımsız terimin toplamıdır. İlk terim Eşitlik (22)'deki gibi ifade edilebilir ve $t$ anına kadar olan verilerden belirlenen en iyi $\phi(t+k)$ tahminini yansıtmaktadır. İkinci terim ise gürültü kaynaklarından, $\mathrm{e}(\mathrm{t}+1), \mathrm{e}(\mathrm{t}+2), \ldots$, $\mathrm{e}(\mathrm{t}+\mathrm{k})$, kaynaklı çıktı tahmin hatası olup Eşitlik (23)'te verilmiştir $[19,20]$.

$$
\begin{aligned}
& \phi\left(t+\left.k\right|_{t}\right)=\frac{1}{C}[(B E+Q C) u(t)+G y(t)-C R r(t)+E d] \\
& E e(t+k)=\phi(t+k)+\phi\left(t+\left.k\right|_{t}\right)
\end{aligned}
$$

Eşitlik (24)’te görüldüğü gibi tahmin edilen çıktı sıfıra eşitlenerek J minimize edilmektedir.

$$
\phi\left(t+\left.k\right|_{t}\right)=0
$$

Burada F ve H Eşitlik (25-26) ile verilmektedir. 
$F=B E+Q C$

$H=C R$

Eşitlik (25-26) kullanılarak Eşitlik (22) düzenlenir ve Eşitlik (27)'deki kontrol yasası elde edilir.

$F u(t)+G y(t)-H r(t)+E d=0$

Bir adım ileri kontrol kanunu giriş değişkenini Eşitlik (28) ile ifade etmektedir [20].

$u(t)=\frac{H r(t)-G y(t)-E d}{F}$

Türetilen eşitliklerin deney sistemindeki karşıllkları ve izlenecek yol: 1. Açık hat sistemde baz akış hızına PRBS sinyali etki olarak verilir ve proses çıktısı $\mathrm{pH}$ elde edilir.2. Baz akış hızı ve pH verileri kullanılarak En Küçük Kareler (EKK) algoritması ile Eşitlik (28)'de yer alan F, G, H, polinomlarının katsayıları belirlenir. $\mathrm{E}=1$ alınmıştır. 3 . Eşitlik (28) ile verilen kontrol çıktısı ifadesinden her adımda baz akış hızını simgeleyen $u(t)$ hesaplanır. $u(t)$ koagülasyon sistemine uygulanarak $\mathrm{pH}$ kontrolü gerçekleştirilir.

\section{DENEYSEL METOT (EXPERIMENTAL METHOD)}

\subsection{En Uygun Koagülant ve pH'ın Belirlenmesi İçin Deney Yöntemi (Experimental Procedure for Determination of Optimum Coagulant and $p H$ )}

$\mathrm{Su}$ bazlı boya atık suyunun koagülasyon yöntemi ile arıtımında kullanılacak en uygun koagülantın belirlenmesi amacıyla $\mathrm{MgCl}_{2}, \mathrm{FeCl}_{3}$ ve $\mathrm{Al}_{2}\left(\mathrm{SO}_{4}\right)_{3}$ ile çalışmalar yapılmıştır. $\mathrm{Bu}$ kapsamda öncelikle $\mathrm{MgCl}_{2}$ koagülantının atık su içerisinde $0,17,0,34,0,51,0,85,1,19 \mathrm{~g} / \mathrm{L}$ derişimlerinde olmasını sağlayacak şekilde $100 \mathrm{~mL}$ hacminde çözeltiler atık suya eklemek amacıyla hazırlanmıştır. Her bir koagülant derişimi ile ayrı ayrı çalışmak üzere 5 adet 500 'er $\mathrm{ml}$ hacminde su bazlı boya atık suyu beherlere alınmıştır. Isıtıcılı manyetik karıştırıcı üzerinde (MTOPS MS300HS) karıştırılan atık sulara hazırlanan $100 \mathrm{~mL}$ koagülant çözeltileri eklenmiş ve $2 \mathrm{~min}$ $400 \mathrm{rpm}$ ve $18 \mathrm{~min} 100 \mathrm{rpm}$ hızda karıștırılmıștır. Her bir beherdeki koagülant eklenerek toplam $600 \mathrm{~mL}$ hacmine ulaşan atık su numuneleri en uygun $\mathrm{pH}$ ve ayarlamada kullanılacak bazın belirlenmesi amacıyla gerçekleştirilecek çalışmalar için $0,27 \mathrm{M} \mathrm{Ca}(\mathrm{OH})_{2}$ ve $0,5 \mathrm{M} \mathrm{NaOH}$ ile muamele edilmek üzere 300 'er $\mathrm{mL}$ hacimde olacak şekilde ikiye bölünmüştür. Beherlerdeki atık su numuneleri 7-12 arasında altı farklı $\mathrm{pH}$ değerine ayarlanmak üzere 50'şer mL'lik daha küçük hacimlere ayrılmıştır. pH ayarlamalarında asit olarak $1,1 \quad \mathrm{M} \quad \mathrm{H}_{2} \mathrm{SO}_{4}$ çözeltisi kullanılmışıı. pH ayarlaması yapılan atık sular $25^{\circ} \mathrm{C}$ 'de $1 \mathrm{~h}$ dinlendirmenin ardından $3000 \mathrm{rpm}$ 'de $10 \mathrm{~min}$ süre ile santrifüjlenmiş ve üst fazın UV spektrofotometresinde (Shimadzu UV-160A) absorbans ölçümleri yapılmıştır. Yukarıda sıralanan işlemler $\mathrm{FeCl}_{3}$ ve $\mathrm{Al}_{2}\left(\mathrm{SO}_{4}\right)_{3}$ koagülantları için tekrar edilmiştir.

\subsection{Proses Kontrol Çalışmalarında Kullanılan Deney Sistemi (Experimental Setup for Process Control Studies)}

Deneysel çalışmalarda Şekil 1'de görülen 2 L hacminde camdan yapılmış ceketli yarı-kesikli bir reaktör, iki peristaltik pompa (WPI-Peristar, USA), bir karıştırıcı (TOPS MS-3020), bir pH metre (EMAF, Türkiye), veri transfer edici (PCM 9901, Commat Instrument Company) ve bilgisayar (IBM 586) kullanılmıştır. Sistemde kullanılan bilgisayarda bulunan $\mathrm{A} / \mathrm{D}$ çevirici kanal ile $\mathrm{pH}$ sinyali (014) voltaj (0-10 v) olarak çevrilmektedir. $\mathrm{pH}$ ayarlamasının yapılması için çalışmalar süresince sisteme yük etkisi olarak

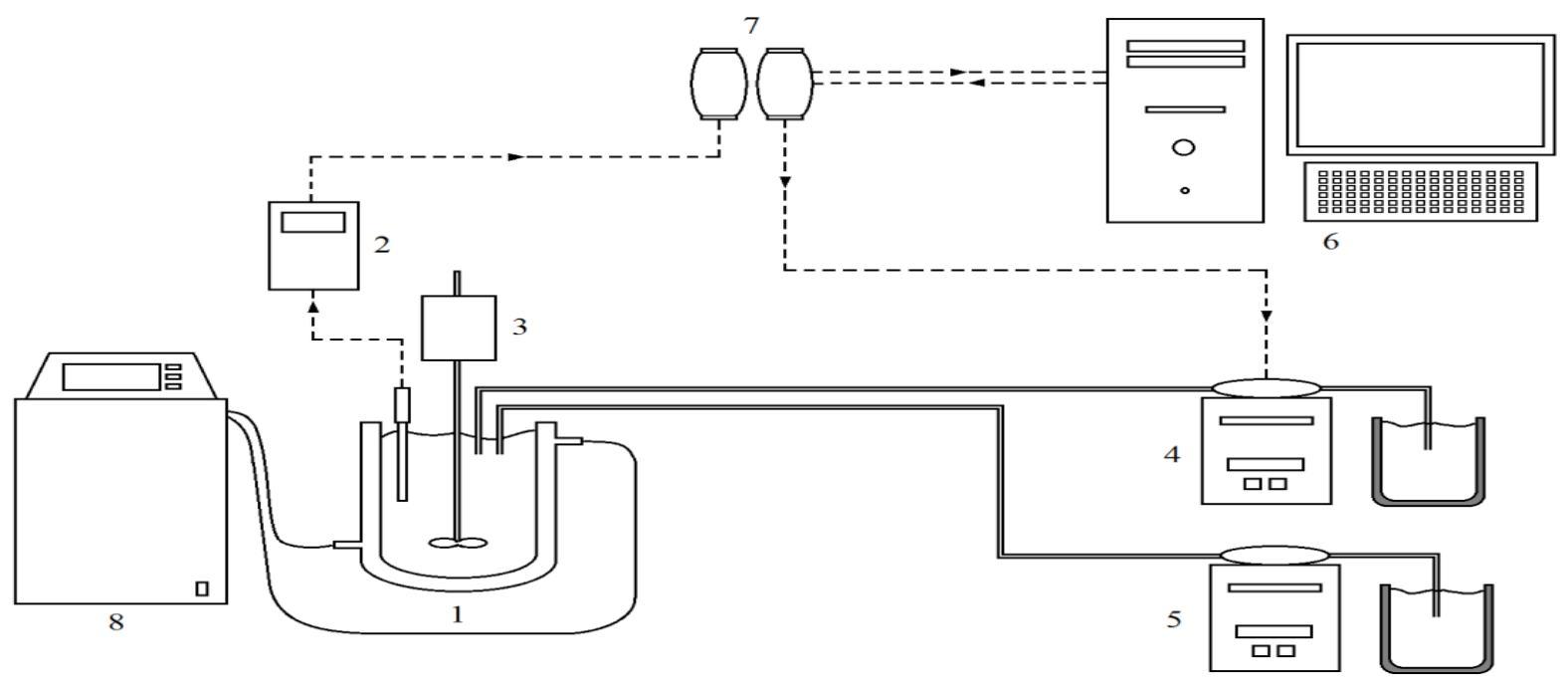

Şekil 1. Deney sistemi (1. Reaktör, 2. pH metre, 3. Karıştıııcı, 4. Asit pompası, 5. Baz pompası, 6. Bilgisayar, 7. Veri transfer edici, 8. Su sirkülatörü)

(Experimental setup (1. Reactor, 2. pH meter, 3. Stirrer, 4. Acid pump, 5. Base pump, 6. Computer, 7. Data acquisition system, 8. Water circulator)) 
bir peristaltik pompa ile $0,030 \mathrm{~mL} / \mathrm{s}$ sabit akış hızında 1,1 $\mathrm{M} \mathrm{H}_{2} \mathrm{SO}_{4}$ beslenmiş, $0,27 \mathrm{M} \mathrm{Ca}(\mathrm{OH})_{2}$ çözeltisinin akış hızı ayarlanabilen değişken olarak seçilmiştir. Çalışmalar bir 1sitmalı/soğutmalı su sirkülatörü (Hoefer RCB 20-PLUS) kullanılarak $25^{\circ} \mathrm{C}$ sabit sicaklık koşullarında gerçekleştirilmiştir. Çalışmalarda reaktöre yerel bir üretim tesisinden temin edilen pH'1 6,5, absorbansı 1,6, bulanıklığı 61,14 NTU ve KOİ değeri $1648,2 \mathrm{mg} / \mathrm{L}$ olan $1 \mathrm{~L}$ su bazlı boya atık suyu beslenmiş, prosesin başlaması için reaktör içerisinde $0,68 \mathrm{~g} / \mathrm{L}$ koagülant derişimini sağlayacak şekilde $7,5 \mathrm{~g} / \mathrm{L}$ derişiminde $100 \mathrm{~mL} \mathrm{Al}\left(\mathrm{SO}_{4}\right)_{3}$ çözeltisi eklenmiştir. Reaktör sistemine çevrim içi bağlı bilgisayarda bulunan Visual Basic programlama diliyle yazılmış bir adım ileri kontrol algoritması ile $\mathrm{pH}$ 'ın istenen değerde tutulması amacıyla kontrol çalışmaları yapılmıştır. Kontrol algoritması yarı dolaylı bir algoritma olup kontrol ayar parametresi olan ağırlık faktörü, $\lambda$, çevrim içi olarak kontrol parametre hesabından etkilenmeksizin değiştirilmiştir. Kontrol algoritmasının ileri besleme fonksiyonu Q ağırlık faktörüne eşit $(\mathrm{Q}=\lambda)$, diğer filtreler olan $\mathrm{P}$ ve $\mathrm{R}$ ise 1 olarak seçilmiştir. Örnekleme süresi 1 saniye olan sistemde $\mathrm{pH}$ ölçümleri veri transfer edici ile bilgisayara çevrim içi olarak aktarılmış, bir adım ileri kontrol algoritması gerekli hesaplamaların yapılmasının ardından ayarlanabilen değişken olan $\mathrm{Ca}(\mathrm{OH})_{2}$ 'nin sisteme iletilmesini sağlayan pompanın hızını değiştirmek amacıyla veri transfer ediciler ile sinyaller göndermiştir. 450 rpm'de 2 min karıştırmanın ardından flokülasyonun sağlanması amacıyla reaktöre $2 \mathrm{~g} / \mathrm{L}$ atık su derişimde ticari polielektrolit eklenerek $150 \mathrm{rpm}$ 'de 18 min karıştırılmıştır. Arıtılan atık su $1 \mathrm{~h}$ dinlenmeye bırakılmış, bu sürenin sonunda 3000 rpm'de 10 min süre ile santrifüjlenerek elde edilen üst fazın UV spektrofotometresinde 290,4 $\mathrm{nm}$ dalga boyunda absorbans ölçümleri yapılmıştır.

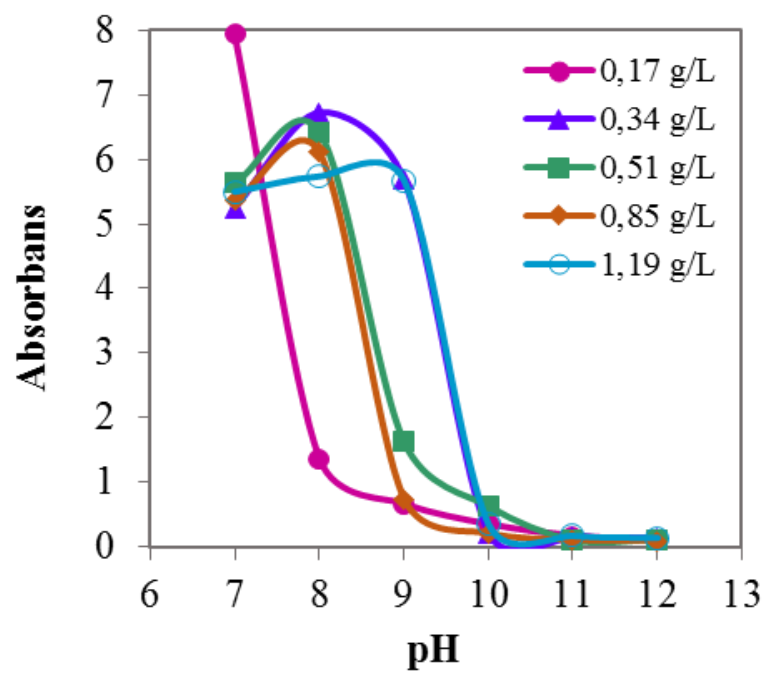

(a)

\section{SONUÇLAR VE TARTIŞMALAR (RESULTS AND DISCUSSIONS)}

\subsection{En Uygun Koagülant ve pH'in Belirlenmesi \\ (Determination of Optimum Coagulant and $\mathrm{pH}$ )}

Kullanılacak koagülant ve çalışılacak pH'ın belirlenmesi amaciyla $\mathrm{MgCl}_{2}, \mathrm{FeCl}_{3}$ ve $\mathrm{Al}_{2}\left(\mathrm{SO}_{4}\right)_{3}$ koagülantları ile yapılan çalışmalar Şekil 2-4'te verilmiştir. Koagülant olarak $\mathrm{MgCl}_{2}$ kullanıldığında Şekil 2 (b)'den de görülebileceği üzere en düşük absorbans $0,85 \mathrm{~g} / \mathrm{L} \mathrm{MgCl}_{2}, \mathrm{pH} 12$ ve baz olarak $\mathrm{Ca}(\mathrm{OH})_{2}$ 'nin kullanıldığ 1 koşullarda 0,065 olarak elde edilmiştir. Atık su deşarj standartlarına uygun $\mathrm{pH}$ aralığı olan 6-9 değerlerinde absorbans değerlerinin diğer koagülantlara göre yüksek çıkması sonucunda $\mathrm{MgCl}_{2}$ ile arıtmanın su bazlı boya atık suyu arıtımı için ekonomik açıdan uygun olmadığı görülmüştür [23]. $\mathrm{FeCl}_{3}$ ve $\mathrm{Al}_{2}\left(\mathrm{SO}_{4}\right)_{3}$ koagülantlarına ait absorbans değerleri kıyaslandığında en düșük absorbans değerinin Șekil 3 (b)'de verildiği üzere $0,85 \mathrm{~g} / \mathrm{L} \quad \mathrm{FeCl}_{3}, \mathrm{pH} 7$ ve baz olarak $\mathrm{Ca}(\mathrm{OH})_{2}$ 'nin kullanıldı $\breve{g}_{1}$ koşullarda 0,038 olarak elde edildiği görülmektedir. Ancak $\mathrm{FeCl}_{3}$ 'ün korozif olmasından dolayı koagülant olarak kullanımı uygun bulunmamıştır [24]. Şekil 4 incelendiğinde $\mathrm{Al}_{2}\left(\mathrm{SO}_{4}\right)_{3}$ koagülant1 kullanılarak $\mathrm{pH}$ ayarlamas $\mathrm{NaOH}$ veya $\mathrm{Ca}(\mathrm{OH})_{2}$ ve $\mathrm{H}_{2} \mathrm{SO}_{4}$ ile yapılan çöktürme işlemlerinde en düşük absorbans değerinin $\mathrm{pH}$ ayarlamasında $\mathrm{Ca}(\mathrm{OH})_{2}$ 'in kullanıldığ durumda 0,068 olarak elde edildiği görülmektedir. $\mathrm{Ca}(\mathrm{OH})_{2}$ literatürde yer alan çalışmalarda hem $\mathrm{pH}$ ayarlayıcı hem de koagülant olarak kullanılmış olup, bu iki işlemin birlikte yürütüldüğü bu çalışmada $\mathrm{Al}_{2}\left(\mathrm{SO}_{4}\right)_{3}$ koagülantı ile sinerjik etki göstermiştir $[8,25,26] . \quad \mathrm{Al}_{2}\left(\mathrm{SO}_{4}\right)_{3}$ koagülantının derişiminin, $\mathrm{pH} 8$ 'de 0,068 absorbans değerini sağlayan iki derişim değerinin $(0,51 \mathrm{~g} / \mathrm{L}$ ve $0,85 \mathrm{~g} / \mathrm{L})$ orta değeri, 0,68 $\mathrm{g} / \mathrm{L}$, olmasına karar verilmiştir. $\mathrm{Bu}$ bilgiler 1 şı̆̆ında,

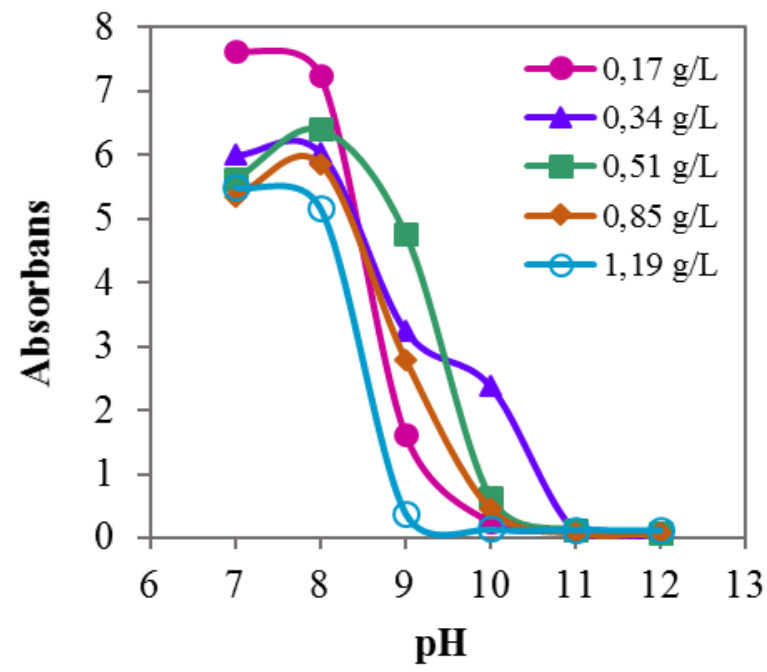

(b)

Şekil 2. Farklı derişimlerde $\mathrm{MgCl}_{2}$ çözeltisi kullanılarak yapılan su bazlı boya atık suyu arıtımında (a) $\mathrm{NaOH}$ (b) $\mathrm{Ca}(\mathrm{OH})_{2}$ ile ayarlaması yapılan $\mathrm{pH}$ değerlerine karşı absorbans değerleri

(Adjustment of $\mathrm{pH}$ with (a) $\mathrm{NaOH}$ (b) $\mathrm{Ca}(\mathrm{OH})_{2}$ versus absorbance values for the treatment of water-based paint wastewater using $\mathrm{MgCl}_{2}$ at different concentrations) 


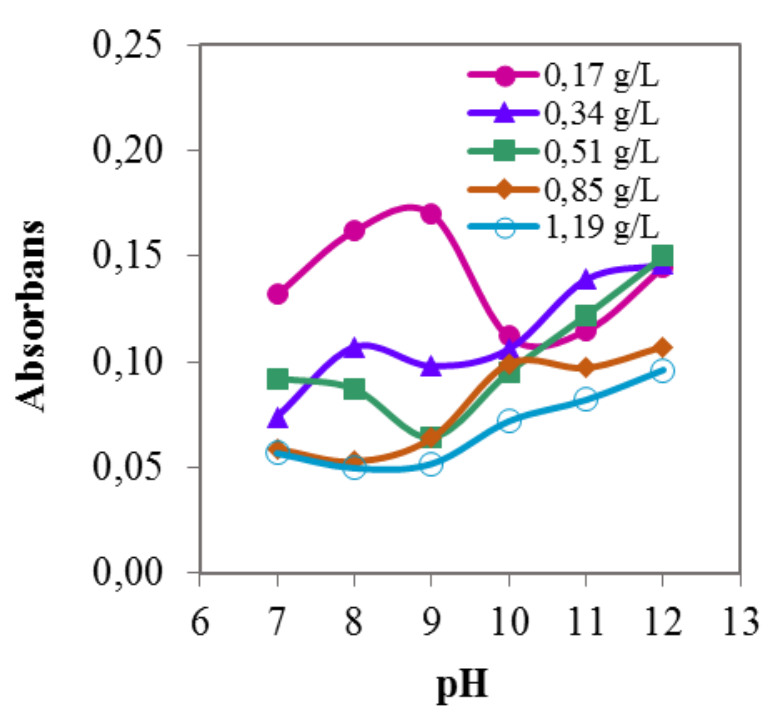

(a)

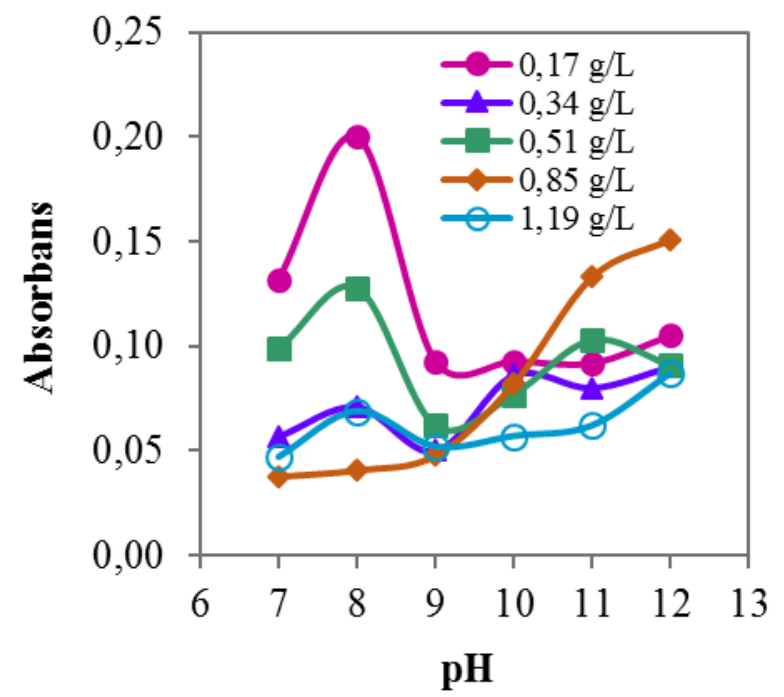

(b)

Şekil 3. Farklı derişimlerde $\mathrm{FeCl}_{3}$ çözeltisi kullanılarak yapılan su bazlı boya atık suyu arıtımında (a) $\mathrm{NaOH}$ (b) $\mathrm{Ca}(\mathrm{OH})_{2}$ ile ayarlaması yapılan $\mathrm{pH}$ değerlerine karșı absorbans değerleri

(Adjustment of $\mathrm{pH}$ with (a) $\mathrm{NaOH}$ (b) $\mathrm{Ca}(\mathrm{OH})_{2}$ versus absorbance values for the treatment of water-based paint wastewater using $\mathrm{FeCl}_{3}$ at different concentrations)

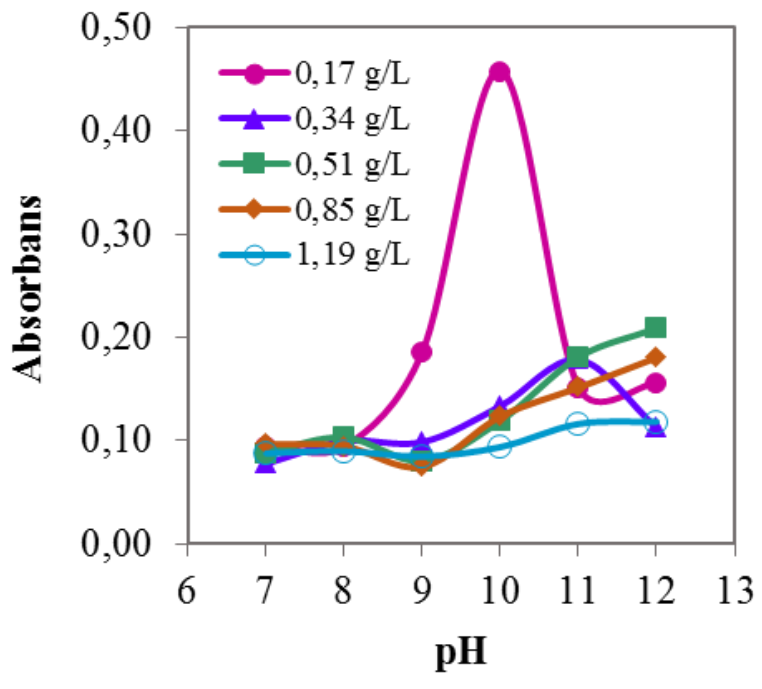

(a)

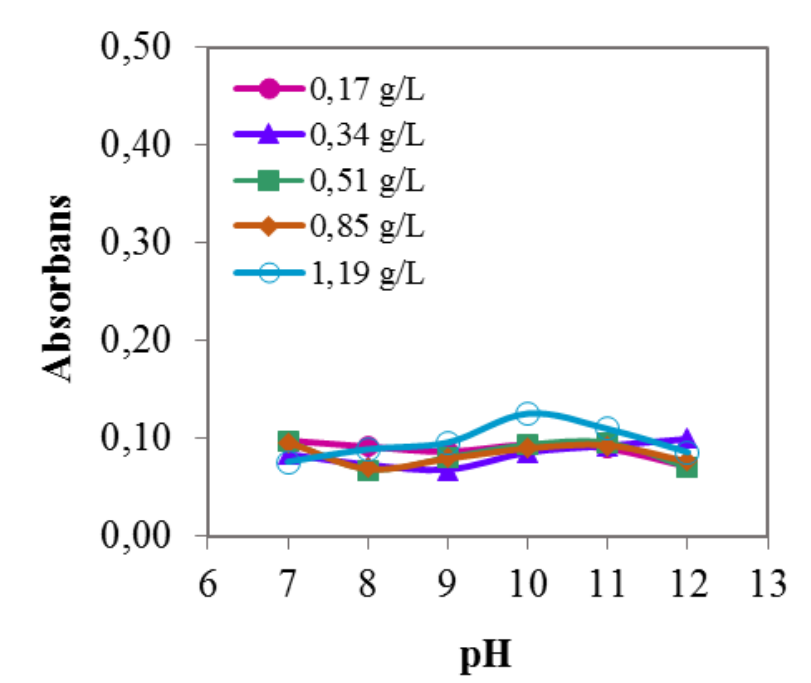

(b)

Şekil 4. Farklı derişimlerde $\mathrm{Al}_{2}\left(\mathrm{SO}_{4}\right)_{3}$ çözeltisi kullanılarak yapılan su bazlı boya atık suyu arıtımında (a) $\mathrm{NaOH}$ (b) $\mathrm{Ca}(\mathrm{OH})_{2}$ ile ayarlaması yapılan $\mathrm{pH}$ değerlerine karşı absorbans değerleri

(Adjustment of $\mathrm{pH}$ with (a) $\mathrm{NaOH}$ (b) $\mathrm{Ca}(\mathrm{OH})_{2}$ versus absorbance values for the treatment of water-based paint wastewater using $\mathrm{Al}_{2}\left(\mathrm{SO}_{4}\right)_{3}$ at different concentrations)

yapılacak kontrol çalışmalarında koagülant olarak $0,68 \mathrm{~g} / \mathrm{L}$ $\mathrm{Al}_{2}\left(\mathrm{SO}_{4}\right)_{3}$, asit çözeltisi olarak $1,1 \mathrm{M} \mathrm{H}_{2} \mathrm{SO}_{4}$ ve baz çözeltisi olarak $0,27 \mathrm{M} \mathrm{Ca}(\mathrm{OH})_{2}$ kullanımına karar verilmiştir.

\subsection{Proses Kontrol Çalı̧̧maları (Process Control Studies)}

Su bazlı boya üretim tesislerinden alınan atık suyun pH'ının istenen değerde tutulması amaciyla bir adım ileri kontrol algoritması ile $\mathrm{pH}$ kontrolü gerçekleştirilmiştir. Kapalı hat bir adım ileri kontrol algoritmasında bulunan $F$ ve $G$ polinomlarının parametreleri için ayarlanabilen değişkene
PRBS sinyal değerleri gönderilerek kontrol edilen değişkenin değişimleri elde edilmiş, bu verilerden yararlanılarak EKK yöntemi ile $F$ ve $G$ değerleri hesaplanmıştır. PRBS sinyal değerleri ile kontrol edilen değişkenin değişimi Şekil 5'te verilmiştir. Bir adım ileri kontrol algoritmasında kullanılmak üzere elde edilen sistem modeli Eşitlik (29)'da verilmiştir.

$$
\begin{aligned}
& -1,07 u(t)+0,0694 u(t-1)=-0,00806 y(t) \\
& -0,00315 y(t-1)+0,00794 y(t-2)-r(t)
\end{aligned}
$$




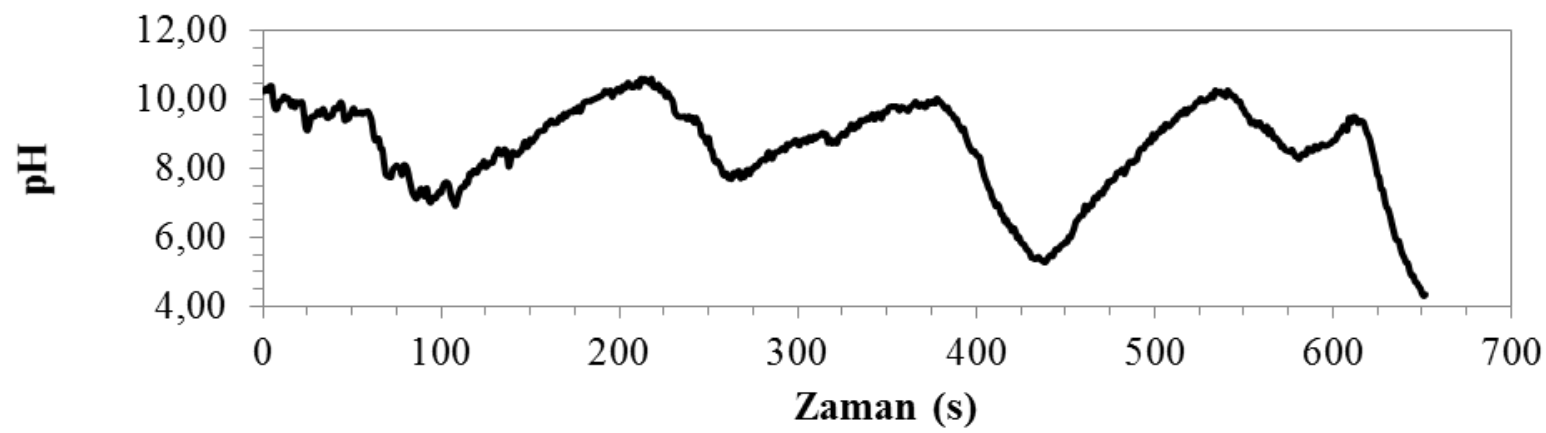

(a)

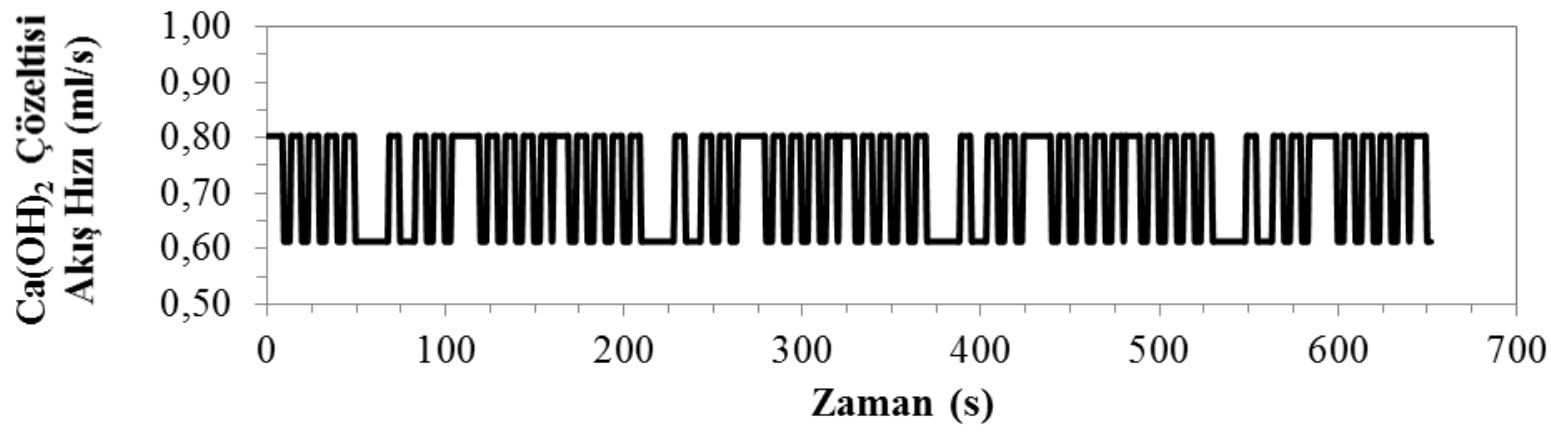

(b)

Şekil 5. (a) PRBS etkisi altındaki sistemde pH'ın zamanla değişimi (b) Ayarlanabilen değişkene gönderilen PRBS sinyal değerleri ((a) pH variation with time under PRBS signals (b) PRBS signals applied to the manipulated variable)

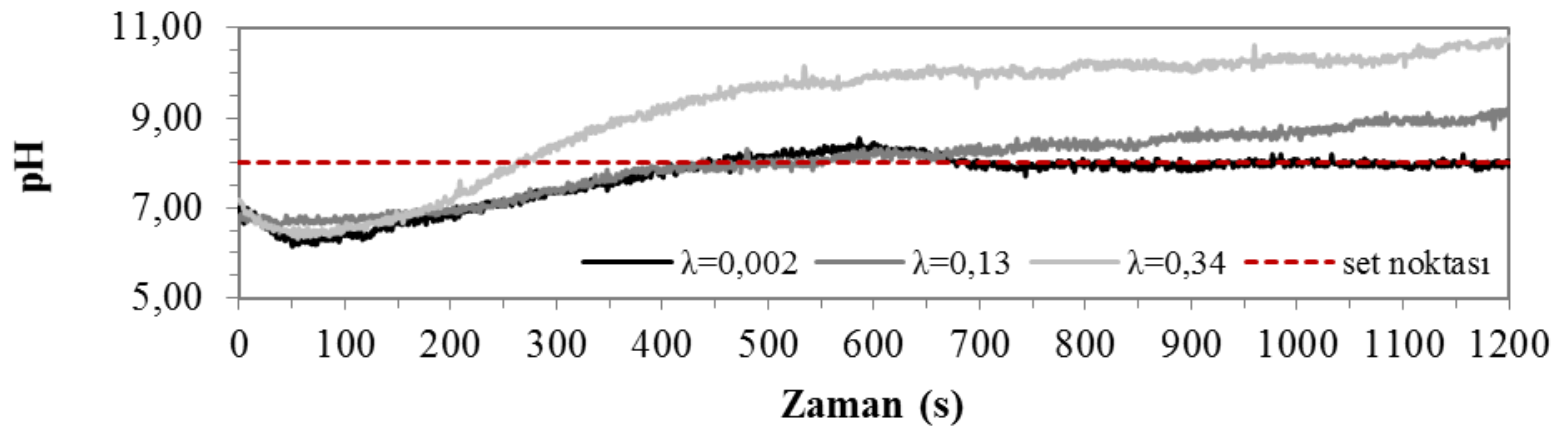

(a)

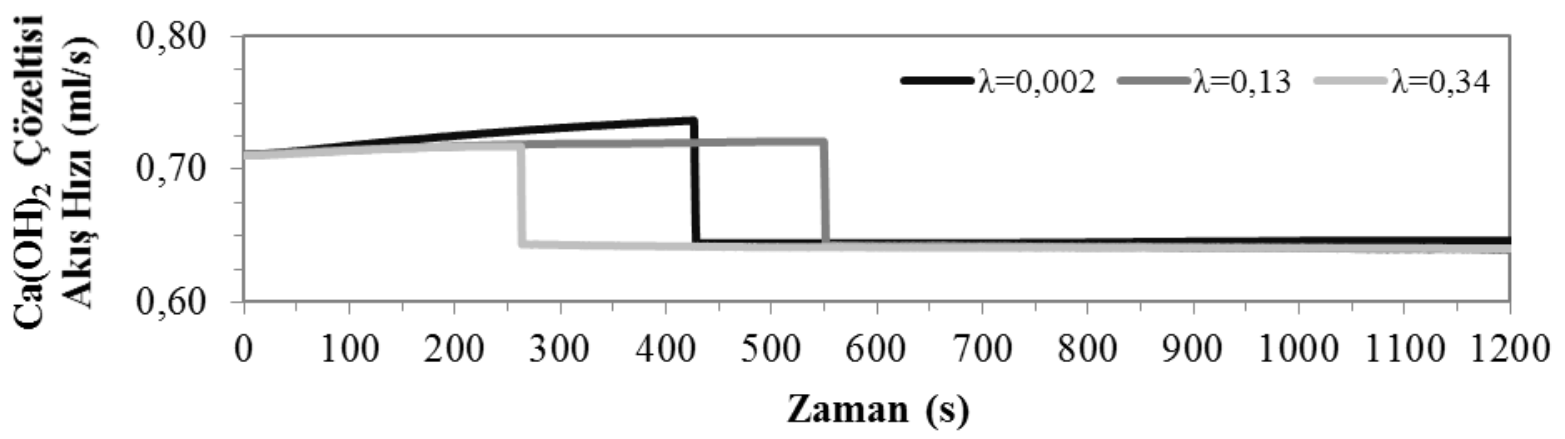

(b)

Şekil 6. Farklı ağırlık faktörü değerlerinde (a) pH'ın (b) ayarlanabilen değişkenin zamanla değişimi (Variation of (a) $\mathrm{pH}$ (b) manipulated variable with time at different control weighting factors) 


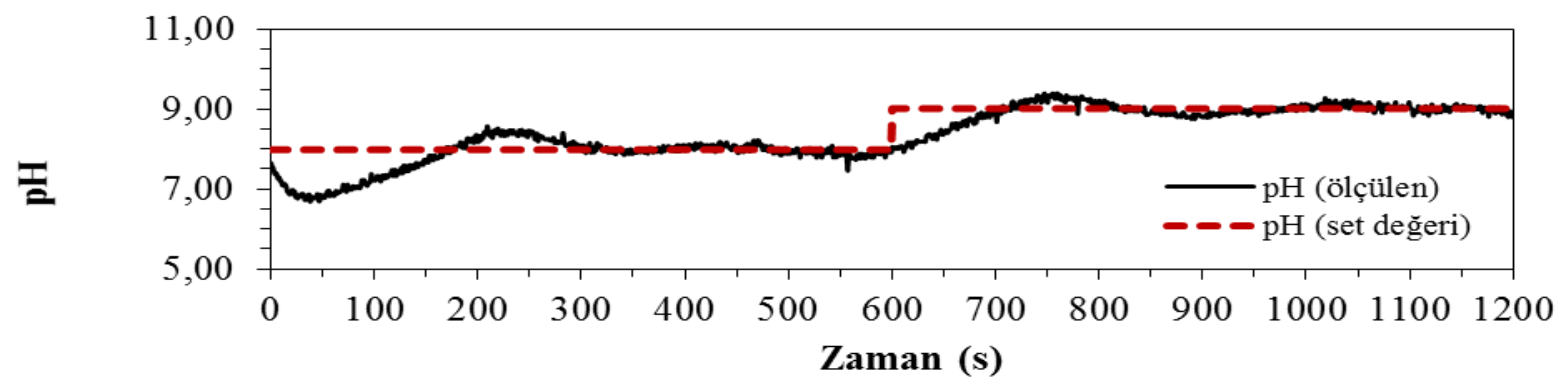

(a)

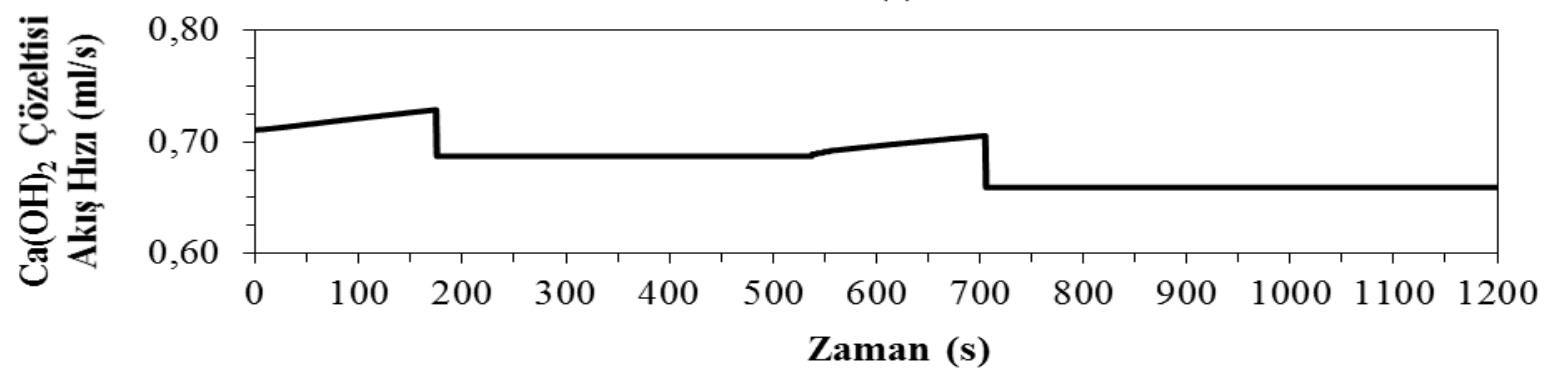

(b)

Şekil 7. Set noktasına pH 8'den 9'a pozitif birim basamak etki verildiği durumda (a) pH'ın (b) ayarlanabilen değişkenin zamanla değişimi (Variation of (a) $\mathrm{pH}$ (b) manipulated variable with time for a positive unit step change to set point from 8 to 9)

Eşitlik (29)'daki sistem modeli elde edildikten sonra pH'ın istenen değerde tutulması için en uygun kontrol ayar parametresi olan ağırlık faktörü $\lambda$ 'nın belirlenmesi amacıyla yapılan çalışmada su bazlı boya atık suyunun koagülasyonla arıtımında en uygun koşullar olan $25^{\circ} \mathrm{C}$ sıcaklık, $0,68 \mathrm{~g} / \mathrm{L}$ $\mathrm{Al}_{2}\left(\mathrm{SO}_{4}\right)_{3}$ koagülant derişiminde sabit set noktası olarak $\mathrm{pH}$ 8 değeri seçilmiştir. Ağırlık faktörü olarak 0,002, 0,13, 0,34 değerleri denenmiş olup, yapılan çalışmanın sonucunda elde edilen $\mathrm{pH}$ ve ayar değişkeni baz akış hızının zamanla değişimi Şekil 6'da verilmiştir. Yapılan kontrol çalışmasına ait hata karesi integrali (ISE), hata mutlak değeri integrali (IAE), zaman ağırlıklı hata mutlak değeri integrali (ITAE) ve zaman ağırlıklı hata karesi integrali (ITSE) performans kriterleri Tablo 1'de verilmiştir.

Tablo 1. Kontrol çalışması için farklı performans kriterlerinin karşılaştırılması

(Comparison of different performance criteria for control studies)

\begin{tabular}{lllll}
\hline$\lambda$ & ISE & IAE & ITAE & ITSE \\
\hline 0,002 & 550,29 & 505,07 & 121426,74 & 77237,17 \\
0,13 & 644,45 & 730,11 & 402537,5 & 304338,2 \\
0,34 & 3924,04 & 2027,29 & 1439007,34 & 3076493,22 \\
\hline
\end{tabular}

Sonuçlardan görüleceği üzere $\lambda$ 'nın 0,002 olduğu durumda en uygun kontrol performansı sağlanmıştır. Kontrol edicinin gürbüzlüğünün test edilmesi amaciyla set noktasına pozitif basamak etki verilmesi durumunun incelendiği bir başka çalışmada $25^{\circ} \mathrm{C}$ sıcaklık ve $0,68 \mathrm{~g} / \mathrm{L} \mathrm{Al}_{2}\left(\mathrm{SO}_{4}\right)_{3}$ koagülant derişiminde ağırlık faktörü 0,002 alınarak set noktası olan pH değerine 8'den 9'a birim basamak etki verilmiştir. Yapılan çalışmanın sonucunda elde edilen $\mathrm{pH}$ ve ayar değişkeni baz akış hızının zamanla değişimi Şekil 7'de verilmiştir. Yapılan kontrol çalışmasına ait ISE, IAE, ITAE, ITSE performans kriterleri surasiyla 182,93, 298,82,
111751,8 ve 44005,87 bulunmuştur. Elde edilen sonuçlar tasarlanan kontrol edicinin koagülasyonla su bazlı boya atık suyunun arıtılmasında $\mathrm{pH}$ değerini istenen değerde tutabileceğini göstermektedir. En uygun proses işletim koşulları $25{ }^{\circ} \mathrm{C}$ sıcaklık ve $0,68 \mathrm{~g} / \mathrm{L} \mathrm{Al}_{2}\left(\mathrm{SO}_{4}\right)_{3}$ koagülant derişiminde $\mathrm{pH} 8$ değerinde $\mathrm{pH}$ kontrollü ve $\mathrm{pH}$ kontrolsüz gerçekleştirilen çalışmalarda kirlilik parametreleri olarak belirlenen absorbans, bulanıklık ve kimyasal oksijen ihtiyacı giderim verimleri (\%) kıyaslanarak Tablo 2'de verilmiştir.

Tablo 2. Su bazlı boya atık suyunun $\mathrm{pH}$ kontrollü ve kontrolsüz arıtımı sonucunda elde edilen giderim verimleri (\%) (Removal efficiencies (\%) of water-based paint wastewater for $\mathrm{pH}$ controlled and uncontrolled treatments)

\begin{tabular}{llll}
\hline $\begin{array}{l}\text { Yapılan } \\
\text { çalışma }\end{array}$ & $\begin{array}{l}\text { Absorbans } \\
\text { Giderimi (\%) }\end{array}$ & $\begin{array}{l}\text { Bulanıklık } \\
\text { Giderimi }(\%)\end{array}$ & $\begin{array}{l}\text { KOİ } \\
\text { Giderimi (\%) }\end{array}$ \\
\hline $\begin{array}{l}\text { pH } \\
\text { Kontrolsüz }\end{array}$ & 93,55 & 79,38 & 22,30 \\
pH & 96,70 & 90,58 & 34,36 \\
Kontrollü & & 9 & \\
\hline
\end{tabular}

\section{SONUÇLAR (CONCLUSIONS)}

Yapılan çalışmada kimyasal çöktürme ve floklaştırma yöntemi ile su bazlı boya atık suyunun arıtımında en uygun çöktürücünün ve ortam pH'ının belirlenmesi amaciyla 0,17 , $0,34,0,51,0,85,1,19 \mathrm{~g} / \mathrm{L}$ derişimlerinde $\mathrm{MgCl}_{2}, \mathrm{FeCl}_{3}$ ve $\mathrm{Al}_{2}\left(\mathrm{SO}_{4}\right)_{3}$ çöktürücüleri ile $\mathrm{pH} 7,8,9,10,11,12$ değerlerinde kesikli deneyler gerçekleştirilmiş ve en uygun çalışma koşulları $25^{\circ} \mathrm{C}$ sicaklık, pH 8, 0,68 g/L Al$\left(\mathrm{SO}_{4}\right)_{3}$ koagülant derişimi olarak belirlenmiştir. $\mathrm{pH}$ ayarlamasında bir koagülant olan $\mathrm{Ca}(\mathrm{OH})_{2}$ kullanılmış olup $\mathrm{Al}_{2}\left(\mathrm{SO}_{4}\right)_{3}$ ile birlikte kullanıldığında $\mathrm{NaOH}$ 'e nazaran kirlilik giderim verimine sinerjik etkisi olduğu görülmüştür. Atık suyun 
pH'inı koagülasyon prosesi boyunca istenen set noktasında tutmak amaciyla bir adım ileri kontrol algoritmas1 kullanılmıştır. Bulunan en uygun çalışma koşullarında üç farklı $\lambda$ değeri kullanılarak kontrol çalışmaları gerçekleştirilmiş ve en uygun değer performans kriterlerinin değerlendirilmesiyle 0,002 olarak elde edilmiştir. Set noktasına pozitif basamak etki verilmesi durumu incelenmiş ve tasarlanan kontrol edicinin koagülasyonla su bazlı boya atık suyunun arıtılmasında $\mathrm{pH}$ değerini istenen değerde başarı ile tutabileceği görülmüştür. Yapılan çalışmada $\mathrm{pH}$ kontrollü gerçekleştirilen arıtımın, $\mathrm{pH}$ kontrolünün yapılmadığı arıtımla kıyaslandığında, absorbans, bulanıklık ve KOİ giderim verimlerini sirasiyla \%3,36, \%14,11, $\% 54,08$ oranında arttırdığı gözlenmiştir.

\section{SIMGELER (SYMBOLS)}

A Kesikli zaman modelinde sistemin kutuplarını belirten monik polinom

B Kesikli zaman modelinde sistemin sifirlarını belirten polinom

C Kesikli zaman modelinde gürültünün sıfırlarını belirten monik polinom

CARMA Controlled Auto Regressive Moving Average

d Ofset

E Bir adım ileri kontrol algoritmasında E polinomu

EKK En küçük kareler

e(t) Rastgele yük

F Bir adım ileri kontrol algoritmasında $\mathrm{F}$ polinomu

G Bir adım ileri kontrol algoritmasında $\mathrm{G}$ polinomu

$\mathrm{H} \quad$ Bir adım ileri kontrol algoritmasında $\mathrm{H}$ polinomu

IAE Hata mutlak değeri integrali

ISE Hata karesi integrali

ITAE Zaman ağırlıklı hata mutlak değeri integrali

ITSE Zaman ağırlıklı hata karesi integrali

J Maliyet fonksiyonu

k Zaman gecikimi

KOİ Kimyasal oksijen ihtiyacı

$\mathrm{n}_{\mathrm{a}} \quad$ A polinomunun derecesi

$\mathrm{n}_{\mathrm{b}} \quad$ B polinomunun derecesi

$\mathrm{n}_{\mathrm{c}} \quad$ C polinomunun derecesi

$\mathrm{n}_{\mathrm{f}} \quad \mathrm{F}$ polinomunun derecesi

$\mathrm{n}_{\mathrm{g}} \quad \mathrm{G}$ polinomunun derecesi

P Çıkış değişkenine etki eden ağırlık polinomu

PRBS Yalancı ikili gelişigüzel etki

Q Kontrol girdisine etki eden ağırlık polinomu

$\mathrm{R} \quad$ Set noktasına etki eden ağılık polinomu

$\mathrm{r}(\mathrm{t}) \quad$ Set noktasi

$\mathrm{u}(\mathrm{t}) \quad$ Ayarlanabilen değişken

$\mathrm{y}(\mathrm{t}) \quad$ Çıkış değişkeni

$\mathrm{Z}^{-1} \quad$ Geri kaydırma işleci

$\Xi \quad$ Beklenti

$\lambda \quad$ Ağırlık faktörü

$\Delta \quad$ Fark işleci

$\phi(\mathrm{t}) \quad$ Yalancı çıktı

$\phi\left(t+\left.k\right|_{t}\right) t$ anına kadar olan verilerden belirlenen en iyi $\phi(t+k)$ tahmini

\section{KAYNAKLAR (REFERENCES)}

1. Dovletoglou O., Philipopoulos C., Grigoropoulou H., Coagulation for treatment of paint industry wastewater, J. Environ. Sci. Health. Part A Toxic/Hazard. Subst. Environ. Eng., A37 (7), 1361-1377, 2002.

2. Dey B.K., Hashim M.A., Hasan S., Sen Gupta B., Microfiltration of water-based paint effluents, Adv. Environ. Res., 8 (3-4), 455-466, 2004.

3. İnan A., Oil pollution modeling in Iskenderun bay, Journal of the Faculty of Engineering and Architecture of Gazi University, 26 (2), 471-478, 2011.

4. Kılıç M., Çepelioğullar Ö., Özsin G., Uzun B.B., Pütün A.E., From Aqueous Solutions Evaluation of Field Debris of Chickpea Husk As a Low-Cost Biosorbent for Removal of Methylene Blue, Journal of the Faculty of Engineering and Architecture of Gazi University, 29 (4), 717-726, 2014.

5. El-Dars F.M.S.E., Ibrahim M.A., Gabr A.M.E., Reduction of COD in water-based paint wastewater using three types of activated carbon, Desalin. Water Treat., 52 (16-18), 2975-2986, 2014.

6. Krithika D., Philip L., Treatment of wastewater from water based paint industries using submerged attached growth reactor, Int. Biodeterior. Biodegrad., 107, 31 41, 2016.

7. Kurt U., Avsar Y., Talha Gonullu M., Treatability of water-based paint wastewater with fenton process in different reactor types, Chemosphere, 64 (9), 15361540, 2006.

8. Mamadiev M., Yilmaz G., Treatment and recycling facilities of highly polluted water-based paint wastewater, Desalin. Water Treat., 26 (1-3), 66-71, 2011.

9. Körbahti B.K., Tanyolaç A., Electrochemical treatment of simulated industrial paint wastewater in a continuous tubular reactor, Chem. Eng. J., 148 (2-3), 444-451, 2009.

10. Silva L.F., Barbosa A.D., Paula H.M., Romualdo L.L., Andrade L.S., Treatment of paint manufacturing wastewater by coagulation/electrochemical methods: Proposals fordisposal and/or reuse of treated water, Water Res., 101, 467-475, 2016.

11. Aboulhassan M.A., Souabi S., Yaacoubi A., Baudu M., Improvement of paint effluents coagulation using natural and synthetic coagulant aids, J. Hazard. Mater., B138 (1), 40-45, 2006.

12. Vishali S., Karthikeyan R., A comparative study of Strychnos potatorum and chemical coagulants in the treatment of paint and industrial effluents: an alternate solution, Sep. Sci. Technol., 49 (16), 2510-2517, 2014.

13. Kalayc1 M.B., Yiğit İ., Theoretical and Experimental Investigation of Some Sliding Mode Control Techniques Used in Practice, Journal of the Faculty of Engineering and Architecture of Gazi University, 30 (1), 131-142, 2015. 
14. Semerjian L., Ayoub G.M., High-pH-magnesium coagulation-flocculation in wastewater treatment, Adv. Environ. Res., 7 (2), 389-403, 2003.

15. Duan J., Gregory J., Coagulation by hydrolysing metal salts, Adv. Colloid Interface Sci., 100-102, 475-502, 2003.

16. Yalçın H. ve Gürü M., Koagülasyon, Su Teknolojisi, Genişletilmiş İkinci Baskı, Palme Yayıncılık, Ankara, 43-47, 2010.

17. Ertunc S., Akay B., Boyacioglu H., Hapoglu H., Selftuning control of dissolved oxygen concentration in a batch bioreactor, Food Bioprod. Process., 87 (1), 46$55,2009$.

18. Çağlayan N., Karacan S., Hapoğlu H., Alpbaz M., Application of optimal adaptive control based on generalized minimum variance to a packed distillation column, Comput. Chem. Eng., 21, 607-612, 1997.

19. Karagöz A.R., Hapoğlu H., Alpbaz M., Generalized minimum variance control of optimal temperature profiles in a polystyrene polymerization reactor, Chem. Eng. Process. Process Intensif., 39 (3), 253-262, 2000.

20. Ertunç S., Akay B., Bursalı N., Hapoğlu H., Alpbaz M., Generalized minimum variance control of growth medium temperature of baker's yeast production, Food Bioprod. Process., 81 (4), 327-335, 2003.
21. Hitit Z.Y., Boyacioglu H., Ozyurt B., Ertunc S., Hapoglu H., Akay B., Self-tuning GMV control of glucose concentration in fed-batch baker's yeast production, Appl. Biochem. Biotechol., 172 (8), 37613775, 2014.

22. Tuncer S., High-Performance Vector Control Strategy for Multilevel Inverter Fed Induction Motor, Journal of the Faculty of Engineering and Architecture of Gazi University, 30 (1), 119-130, 2015.

23. Su Kirliliği Kontrolü Yönetmeliği, Resmi Gazete Sayı 25687, 31 Aralık 2004.

24. Demir (III) Klorür Malzeme Güvenlik Bilgi Formu, MSDS No 157740, Sigma Aldrich, 2015.

25. Chowdhury M., Mostafa M.G., Biswas T.K., Saha A.K., Treatment of leather industrial effluents by filtration and coagulation process, Water Resour. Ind., 3, 11-22, 2013.

26. Meriç S., Guida M., Anselmo A., Mattei M.L., Melluso G., Pagano G., Microbial and COD removal in a municipal wastewater treatment plant using coagulation flocculation process, J. Environ. Sci. Health. Part A Toxic/Hazard. Subst. Environ. Eng., 37 (8), 14831494, 2002. 